\title{
Polpa Cítrica em Dietas de Vacas em Lactação. 1. Consumo de Nutrientes, Produção e Composição do Leite ${ }^{1}$
}

\author{
Anderson Jorge de Assis ${ }^{2}$, José Maurício de Souza Campos ${ }^{3}$, Sebastião de Campos Valadares \\ Filho $^{3}$, Augusto César de Queiroz ${ }^{3}$, Rogério de Paula Lana ${ }^{3}$, Ricardo Frederico Euclydes ${ }^{3}$, \\ Josué Mendes Neto ${ }^{2}$, André Luiz Rodrigues Magalhães ${ }^{2}$, Sandro de Souza Mendonça ${ }^{4}$
}

RESUMO - Doze vacas lactantes, da raça Holandesa puras e mestiças, com peso vivo médio inicial de 550 kg, foram distribuídas em três quadrados latinos. O período experimental foi de 18 dias, sendo sete dias de adaptação à dieta e onze dias para coleta de dados. A alimentação fornecida foi para atender os requerimentos de vacas não gestantes produzindo $20 \mathrm{~kg}$ de leite com $4,5 \%$ de gordura, com o objetivo de avaliar os efeitos da substituição $(0,33,67,100 \%)$ do milho pela polpa cítrica em dietas completas no consumo dos nutrientes, produção e composição do leite e variação de peso. Não houve diferença para produção de leite sem e com correção para 4\% de gordura, teor de gordura, proteína, extrato seco total, extrato seco desengordurado. O consumo dos nutrientes não foi afetado pela dieta, exceto para o consumo de extrato etéreo, mostrando decréscimo de $0,47 \mathrm{~g}$ para cada $1 \%$ de substituição do fubá de milho pela polpa cítrica adicionada na dieta. A polpa cítrica pode substituir até $100 \%$ do milho em dietas completas para vacas produzindo em média $20 \mathrm{~kg}$ de leite.

Palavras-chave: alimentação, dieta total, silagem de sorgo, variação de peso

\section{Citrus Pulp in Diets for Milking Cows. 1. Intake of Nutrients, Milk Production and Composition}

\begin{abstract}
Twelve milking cows, purebred and crossbred Holstein, with average weight of $550 \mathrm{~kg}$, were allotted to three Latin Squares 4 x 4 . The experimental period lasted 18 days, seven days for the adaptation to the diets and eleven days for data collection. Feeding was supplied to met the requirements of non pregnant cows, producing $20 \mathrm{~kg}$ of milk with $4.5 \%$ fat. This work aimed to evaluate the effects of replacement $(0,33,67,100 \%)$ of corn meal by pelleted citrus pulp in the concentrate in total mixed rations, on nutrients intake, milk production and composition and weight variation. The treatments did not differ for milk production and composition with or without correction for $4 \%$ fat, fat content, protein, total dry extract, degreased dry extract. The nutrients intake was not affected by level of replacement of corn meal by citrus pulp. However, the ether extract intake decreased $0.47 \mathrm{~g}$ for each $1 \%$ increase in citrus pulp in the concentrate. The citrus pulp can replace up to $100 \%$ of the corn in total mixed rations for lactating cows
\end{abstract}

Key Words: feeding, sorghun silage, total mixed rations, weight variation

\section{Introdução}

A pecuária de leite passa por profundas transformações econômicas nesses últimos anos, tanto no âmbito da produção primária, quanto no processamento e distribuição. Dentro dessa nova realidade, a estratégia de gestão orienta-se no sentido da redução dos custos de produção, visto que praticamente não há como os produtores influenciarem os preços recebidos (Silva Neto, 2000).

A polpa cítrica é um dos subprodutos da indústria alimentícia de grande utilização na alimentação de ruminantes em todo o mundo, com destaque para os países europeus e os Estados Unidos, onde neste último, $90 \%$ da polpa cítrica desidratada é utilizada na alimentação de vacas em lactação (Ammerman \& Henry, 1991). Já para os países europeus, a polpa é utilizada principalmente quando a forragem é pouco disponível ou de baixa qualidade (Madrid et al., 1997).

A polpa cítrica possui em torno de $85-90 \%$ do valor energético do milho e teor de proteína bruta baixo $(7,1 \% \pm 0,49$ base matéria seca). Com relação aos carboidratos, apresenta alto teor de carboidratos solúveis e a sua parede celular é altamente digestível, apresentando em sua composição grande proporção de pectina - um carboidrato estrutural de alta e rápida degradação, estando prontamente disponível, cujo produto final da fermentação é o ácido acético. Este 
ácido é um dos principais precursores da gordura do leite, por isso, sugere-se que a polpa cítrica pode auxiliar na manutenção de altas porcentagens de gordura do leite em condições onde o volumoso é escasso ou de baixa qualidade (Rocha Filho, 1998).

No Brasil, a média da produção de polpa cítrica nas safras de 96/97 até 99/00 chegou a 1,23 milhões de toneladas (Abecitrus, 2001). Despertou-se, nesses últimos anos, o interesse por este subproduto apesar do país exportar a polpa cítrica peletizada desde 1970. Uma das justificativas para este interesse é a redução de preço no mercado externo e interno, chegando a alcançar preços inferiores ao milho. Esta baixa no preço tornou a polpa cítrica economicamente atraente. Entretanto, como a sua utilização na alimentação animal é recente no Brasil, são poucas as pesquisas sobre os seus benefícios em relação aos aspectos nutricionais, produtivos e econômicos na alimentação de vacas leiteiras nas condições brasileiras. Talvez, devido à falta dessas informações, muitos produtores deixam de utilizar a polpa cítrica na alimentação de seus animais com receio de que este produto possa diminuir o desempenho ou até mesmo afetar a saúde de seus animais. Este fato ocorre não somente com a polpa, mas com vários outros alimentos que possam substituir os alimentos tradicionais que são o milho e a soja. Este tradicionalismo geralmente impede que o produtor possa melhorar sua eficiência econômica e manter-se mais competitivo no mercado.

Segundo Belém \& Soares Filho (1999), em extensa revisão de literatura sobre o envolvimento da polpa cítrica em quadros referidos como intoxicação e caracterizados, em linhas gerais, por uma síndrome hemorrágica, febre e prurido, não conseguiram relacionar tal fato com o uso de polpa cítrica. Entretanto, ressaltaram possível contaminação que pudesse ocorrer em virtude de problemas climáticos, ou, até mesmo, desacerto na utilização do produto. Os mesmos autores ainda registraram que quadros clínicos em bovinos, como síndrome hemorrágicas, prurido e febre, foram também associados ao consumo de milho, cevada, resíduo úmido de cervejaria, feno e silagens, mas em nenhuma das vezes se conseguiu determinar a etiologia, ficando como principal suspeita o envolvimento de micotoxinas sem qualquer comprovação.

O consumo de alimentos determina o nível de ingestão dos nutrientes e dessa forma o desempenho animal. Alguns estudos avaliaram níveis de inclusão de polpa cítrica e seu efeito no consumo de matéria seca.
Os resultados mostraram que a polpa cítrica não afetou o consumo de nutrientes (Menezes Jr. et al., 2000; Ítavo, 1998; Belibasakis \& Tsirgogianni, 1995). Todavia, Nussio et al. (2000) compararam formas de processamento do grão de milho (grão moído fino e grosso e milho floculado) e a inclusão de polpa cítrica substituindo $50 \%$ da MS do milho moído fino ou floculado em dietas contendo 53\% de silagem de milho em dietas de vacas em lactação. A polpa cítrica, associada ao milho floculado, promoveu menor consumo nos animais em relação à substituição parcial do milho moído fino (16,1 vs 19,6 kg de MS). Estes resultados mostram que, dependendo do ingrediente da dieta, a polpa cítrica pode influenciar o consumo dos nutrientes.

Como a substituição de cereais ricos em amido por polpa cítrica resulta em maiores concentrações de ácido acético, e sendo este um dos principais precursores da gordura do leite, sugere-se que a polpa cítrica pode auxiliar a manutenção de altas porcentagens de gordura do leite. A literatura é discordante quanto aos resultados encontrados para teor de gordura e produção de leite corrigida para gordura, mostrando que o fornecimento de polpa cítrica tanto pode aumentar estes parâmetros (Menezes et al. 2000; Belibasakis \& Tsirgogianni, 1996; Lucci et al. 1975 citados por Carvalho, 1995; Van Horn et al. 1975), quanto pode resultar em nenhuma alteração na composição e produção de leite corrigida para gordura ou não (Ítavo, 1998; Fegeros et al. 1995).

Existe tendência atual, motivada principalmente por fatores econômicos e ambientais, em substituir grãos de cereais por subprodutos (Rocha Filho, 1998). Sutton et al. (1987) comentaram que a consequência nutricional desta mudança é que o amido é substituído pela fibra como principal fonte de energia e que pouco é conhecido sobre os efeitos desta mudança, na produção de leite, consumo e digestibilidade dos volumosos. Assim, tendo em vista a escassez de informações na literatura, realizou-se o presente estudo com o objetivo de avaliar o efeito da polpa cítrica no consumo de nutrientes, produção e composição do leite em animais característicos da pecuária brasileira.

\section{Material e Métodos}

O experimento foi realizado no Setor de Bovinos do Departamento de Zootecnia (DZO), da Universidade Federal de Viçosa (UFV), Viçosa (MG), durante o período de setembro a novembro de 1999. 
Foram utilizadas 12 vacas da raça Holandesa Preto e Branco, puras e mestiças, não gestantes, no terço médio da lactação e peso vivo médio inicial de $550 \mathrm{~kg}$, distribuídas em três quadrados latinos, 4 x 4, balanceados.

O experimento foi constituído de quatro períodos com duração de 18 dias cada um, sendo os sete primeiros dias de adaptação e os demais para avaliação do consumo de nutrientes, produção e composição do leite e variação de peso.

Os dados obtidos foram submetidos à análise de variância e de regressão ao nível de significância de 5\%, utilizando-se o programa SAEG, versão 7.0 (UFV, 1997). Como tratamento é uma variável contínua (nível de substituição), os graus de liberdade deste efeito foram desdobrados em efeito linear, quadrático e cúbico.

Os animais receberam quatro dietas completas, contendo 0, 33, 67 e 100\% de polpa cítrica em substituição ao fubá de milho, na matéria seca (MS). Foram usados, no balanceamento das dietas, como alimento concentrado polpa cítrica, fubá de milho, farelo de soja, premix mineral e vitamínico e como

Tabela 1 - Composição percentual dos ingredientes utilizados nos concentrados experimentais (\% na MS)

Table 1 - Percentage composition of the ingredients used in the experimental concentrates (\%DM)

\begin{tabular}{|c|c|c|c|c|}
\hline $\begin{array}{l}\text { Ingredientes } \\
\text { Ingredients }\end{array}$ & & $\begin{array}{l}1 \mathrm{de} p \mathrm{pc} \\
\text { trus pr }\end{array}$ & $\begin{array}{l}\text { a cítri } \\
\text { level }\end{array}$ & $\%$ \\
\hline & 0 & 33 & 67 & 100 \\
\hline $\begin{array}{l}\text { Polpa cítrica } \\
\text { Citrus pulp }\end{array}$ & 0,0 & 15,1 & 30,3 & 45,0 \\
\hline $\begin{array}{l}\text { Fubá de milho } \\
\text { Corn meal }\end{array}$ & 45,4 & 30,3 & 15,1 & 0,0 \\
\hline $\begin{array}{l}\text { Farelo de soja } \\
\text { Soybean meal }\end{array}$ & 25,6 & 25,6 & 25,6 & 25,6 \\
\hline $\begin{array}{l}\text { Farelo de trigo } \\
\text { Wheat meal }\end{array}$ & 12,2 & 12,2 & 12,2 & 12,2 \\
\hline $\begin{array}{l}\text { Farelo de algodão } \\
\text { Cotton meal }\end{array}$ & 12,2 & 12,2 & 12,2 & 12,2 \\
\hline $\begin{array}{l}\text { Uréia } \\
\text { Urea }\end{array}$ & 1,3 & 1,5 & 1,7 & 1,9 \\
\hline $\begin{array}{l}\text { Fosfato bicálcico } \\
\text { Dicalcium phosphate }\end{array}$ & 1,0 & 1,0 & 1,0 & 1,0 \\
\hline $\begin{array}{l}\text { Calcário calcítico } \\
\text { Limestone }\end{array}$ & 1,0 & 0,8 & 0,6 & 0,4 \\
\hline $\begin{array}{l}\text { Sal mineralizado }{ }^{1} \\
\text { Mineral mix }\end{array}$ & 1,3 & 1,3 & 1,3 & 1,3 \\
\hline
\end{tabular}

volumoso silagem de sorgo. Os ingredientes para formulação do concentrado foram adquiridos, misturados e doados pela empresa Agroceres Nutrição Animal LTDA. A relação volumoso : concentrado foi de 55:45, base MS. Após análise dos ingredientes disponíveis, as dietas foram formuladas conforme requerimentos do NRC (1989).

A composição dos concentrados e das dietas experimentais, formuladas de acordo com o NRC (1989), encontra-se nas Tabelas 1 e 2. Periodicamente foram feitas estimativas do teor da MS do volumoso, para ajuste da relação volumoso:concentrado das dietas ao longo dos períodos experimentais.

No momento da alimentação foram feitas amostragens das dietas e sobras que foram acondicionadas em sacos plásticos e congeladas para posteriores análises.

Na Tabela 3, encontra-se a composição bromatológica média dos concentrados e da silagem de sorgo utilizada nos quatros períodos experimentais, enquanto a Tabela 4 mostra a composição bromatológica média das dietas experimentais. Observaram-se teores crescentes de fibra em detergen-

Tabela 2 - Composição percentual dos ingredientes utilizados nas dietas experimentais (\% na MS)

Table 2 - Percentage composition of the ingredients used in the experimental diets (\%DM)

\begin{tabular}{|c|c|c|c|c|}
\hline \multirow[t]{2}{*}{$\begin{array}{l}\text { Ingredientes } \\
\text { ingredients }\end{array}$} & \multicolumn{4}{|c|}{$\begin{array}{c}\text { Nivel de polpa cítrica (\%) } \\
\text { Citrus pulp level (\%) }\end{array}$} \\
\hline & 0 & 33 & 67 & 100 \\
\hline $\begin{array}{l}\text { Silagem de sorgo } \\
\text { Sorghun silage }\end{array}$ & 55,00 & 55,00 & 55,00 & 55,00 \\
\hline Polpa cítrica & 0 & 6,80 & 13,63 & 20,43 \\
\hline $\begin{array}{l}\text { Citrus pulp } \\
\text { Fubá de milho } \\
\text { Corn meal }\end{array}$ & 20,43 & 13,63 & 6,80 & 0 \\
\hline $\begin{array}{l}\text { Farelo de soja } \\
\text { Soybean meal }\end{array}$ & 11,50 & 11,50 & 11,50 & 11,50 \\
\hline $\begin{array}{l}\text { Farelo de trigo } \\
\text { Wheat meal }\end{array}$ & 5,50 & 5,50 & 5,50 & 5,50 \\
\hline Farelo de algodão & 5,50 & 5,50 & 5,50 & 5,50 \\
\hline $\begin{array}{l}\text { Uréia } \\
\text { Urea }\end{array}$ & 0,60 & 0,68 & 0,75 & 0,85 \\
\hline $\begin{array}{l}\text { Fosfato bicálcico } \\
\text { Dicalcium phosphate }\end{array}$ & 0,45 & 0,45 & 0,45 & 0,45 \\
\hline $\begin{array}{l}\text { Calcário calcítico } \\
\text { Limestone }\end{array}$ & 0,44 & 0,36 & 0,29 & 0,19 \\
\hline $\begin{array}{l}\text { Limestone } \\
\text { Sal mineralizado } 1 \\
\text { Mineral mix }\end{array}$ & 0,58 & 0,58 & 0,58 & 0,58 \\
\hline
\end{tabular}


Tabela 3 - Teores médios de matéria seca (MS), matéria orgânica (MO), proteína bruta (PB), extrato etéreo (EE), carboidratos totais $(\mathrm{CHO})$, fibra em detergente neutro (FDN), carboidratos não fibrosos (CNF), fibra em detergente ácido (FDA) e lignina (Lig) dos concentrados e da silagem de sorgo

Table 3 - Average contents of dry matter (DM), organic matter $(O M)$, crude protein $(C P)$, ether extract $(E E)$, total carbohydrates (CHO), neutral detergent fiber (NDF), nonstructural carbohydrates (NSC), acid detergent fiber (ADF) and lignin (Lig) of the concentrates and sorghun silage

\begin{tabular}{|c|c|c|c|c|c|}
\hline \multirow[t]{2}{*}{$\begin{array}{l}\text { Itens } \\
\text { Items }\end{array}$} & \multicolumn{4}{|c|}{$\begin{array}{c}\text { Nivel de polpa cítrica }(\%) \\
\text { Citrus pulp level (\%) }\end{array}$} & \multirow[t]{2}{*}{$\begin{array}{l}\text { Silagem } \\
\text { Silage }\end{array}$} \\
\hline & 0 & 33 & 67 & 100 & \\
\hline $\mathrm{MS} \%$ & 87,0 & 87,9 & 88,2 & 88,4 & 25,0 \\
\hline $\begin{array}{l}\% D M \\
\mathrm{MO}^{1}\end{array}$ & 93,4 & 93,3 & 92,4 & 91,7 & 93,4 \\
\hline $\begin{array}{l}O M \\
\mathrm{~PB}^{1}\end{array}$ & 27,4 & 25,9 & 28,3 & 25,9 & 4,0 \\
\hline$C P$ & & & & & \\
\hline $\mathrm{EE}^{1}$ & 3,5 & 3,2 & 3,0 & 2,7 & 2,3 \\
\hline $\mathrm{CHO}^{1}$ & 63,5 & 65,1 & 62,2 & 63,3 & 86,3 \\
\hline $\mathrm{FDN}^{1}$ & 19,1 & 19,5 & 23,2 & 23,3 & 68,1 \\
\hline$N D F$ & & & & & \\
\hline $\begin{array}{l}\mathrm{CNF}^{1} \\
N S C\end{array}$ & 44,4 & 45,6 & 39,0 & 40,0 & 18,2 \\
\hline $\begin{array}{l}\text { FDA }^{1} \\
A D F\end{array}$ & 9,7 & 10,3 & 10,1 & 12,8 & 38,0 \\
\hline Lig. 1 & 1,9 & 2,0 & 2,4 & 3,1 & 6,0 \\
\hline
\end{tabular}

${ }_{1}^{1}$ Porcentagem da MS (DM percentage).

te neutro, fibra em detergente ácido e lignina, à medida que o fubá de milho foi substituído pela polpa cítrica. Este fato é explicado em virtude de a polpa cítrica ser mais rica nestas frações em relação ao milho.

Após o parto, as vacas foram manejadas em curral coletivo para vacas em início de lactação, recebendo como alimentação silagem de milho a vontade e $1 \mathrm{~kg}$ de concentrado para cada $2,5 \mathrm{~kg}$ de leite produzido em duas refeições diárias (sistema de produção adotado pelo Setor de bovinos do $\mathrm{DZO} / \mathrm{UFV}$ ).

Após atingirem o pico da lactação, as vacas foram transferidas para baias individuais cobertas, tipo "tie stall", com piso de cimento, contendo comedouros e bebedouros individuais. $\mathrm{O}$ piso era limpo todos os dias quando os animais eram retirados para a ordenha.

As vacas foram ordenhadas mecanicamente, duas vezes ao dia, fazendo-se o registro da produção de leite (PL). Foi coletada uma amostra de leite de cada
Tabela 4 - Teores médios de matéria seca (MS), matéria orgânica (MO), proteína bruta (PB), extrato etéreo (EE), carboidratos totais ( $\mathrm{CHO}$ ), fibra em detergente neutro (FDN), carboidratos não fibrosos (CNF), fibra em detergente ácido (FDA), lignina (Lig) e nutrientes digestíveis totais (NDT) obtidos para as dietas experimentais

Table 4 - Average contents of dry matter (DM), organic matter $(O M)$, crude protein $(C P)$, ether extract $(E E)$, total carbohydrates (CHO), neutral detergent fiber (NDF), nonstructural carbohydrates (NSC), acid detergent fiber (ADF), lignin (LIG) and total digestible nutrients (TDN) obtained for the experimental diets

\begin{tabular}{|c|c|c|c|c|}
\hline \multirow[t]{2}{*}{$\begin{array}{l}\text { Itens } \\
\text { Items }\end{array}$} & \multicolumn{4}{|c|}{$\begin{array}{l}\text { Nivel de polpa cítrica (\%) } \\
\text { Citrus pulp level (\%) }\end{array}$} \\
\hline & 0 & 33 & 67 & 100 \\
\hline MS \% & 52,9 & 53,3 & 53,4 & 53,5 \\
\hline $\begin{array}{l}\% D M \\
\mathrm{MO}^{1}\end{array}$ & 93,4 & 93,3 & 92,9 & 92,6 \\
\hline $\begin{array}{l}O M \\
\mathrm{~PB}^{1} \\
C P\end{array}$ & 14,5 & 13,8 & 14,9 & 13,8 \\
\hline $\mathrm{EE}^{1}$ & 2,8 & 2,7 & 2,6 & 2,5 \\
\hline $\mathrm{CHO}^{1}$ & 75,6 & 76,3 & 75,0 & 75,5 \\
\hline $\mathrm{FDN}^{1}$ & 46,0 & 46,2 & 47,9 & 47,9 \\
\hline$N D F$ & & & & \\
\hline $\mathrm{CNF}$ & 29,6 & 30,1 & 27,1 & 27,6 \\
\hline $\begin{array}{l}\text { NSC } \\
\text { FDA }^{1}\end{array}$ & 25,2 & 25,5 & 25,4 & 26,6 \\
\hline $\begin{array}{l}A D F \\
\text { Lig. }{ }^{1} \\
\text { NDT }^{1}\end{array}$ & $\begin{array}{r}4,2 \\
72,4\end{array}$ & $\begin{array}{r}4,2 \\
718\end{array}$ & $\begin{array}{r}4,4 \\
722\end{array}$ & $\begin{array}{r}4,7 \\
707\end{array}$ \\
\hline$T D N$ & & & & \\
\hline
\end{tabular}

${ }^{1}$ Porcentagem da MS (DM percentage).

tratamento na ordenha da manhã e da tarde no $12^{\underline{o}} \mathrm{e}$ $15^{\circ}$ dia, para fins de análise dos teores de proteína bruta $(\mathrm{PB})$, gordura do leite $(\mathrm{G})$ e estimativa do extrato seco total (EST) e desengordurado (ESD).

No início e no final de cada período foram feitas pesagens de cada vaca. Os pesos nestas épocas foram as médias de duas pesagens diárias, feitas antes do fornecimento das alimentações e após as ordenhas. A alimentação era fornecida em duas refeições diárias, ad libitum, às 8 e $16 \mathrm{~h}$, permitindo-se sobras de até $10 \%$.

As análises de matéria seca (MS), matéria orgânica (MO), compostos nitrogenados totais (Nt), extrato etéreo (EE), fibra em detergente neutro (FDN), fibra detergente ácido (FDA) e lignina (Lig) foram feitas segundo Silva (1990). A FDN foi corrigida para cinza. Os carboidratos totais $(\mathrm{CHO})$, carboidratos não fibrosos (CNF) e nutrientes digestíveis totais (NDT), foram calculados segundo Sniffen et al. (1992), em que: 


$$
\begin{gathered}
\mathrm{CHO}=100-(\% \mathrm{~PB}+\% \mathrm{EE}+\% \mathrm{CINZAS}) ; \\
\mathrm{CNF}=\mathrm{CHO}-\mathrm{FDN} \\
\mathrm{NDT}=(\text { PBing }- \text { PBfecal })+(\mathrm{CT} \text { ing }- \text { CTfecal })+ \\
2,25(\text { EEing }- \text { EEfecal }),
\end{gathered}
$$

em que: $\mathrm{PBing}=\mathrm{PB}$ ingerida CTing $=\mathrm{CT}$ ingerido $\mathrm{e}$ EEing $=$ EE ingerido.

Para corrigir a produção de leite para 4,0\% de gordura (PLG), utilizou-se à equação do NRC (1989): $\mathrm{PLG}=0,4(\mathrm{~kg}$ de leite $)+15(\mathrm{~kg}$ de gordura $)$. A determinação do extrato seco total (EST) e desengordurado (ESD) do leite foi feita pelo método de Gerber (Behmer, 1984).

O teor de nitrogênio total do leite, analisado pelo método micro Kjeldahl (Silva, 1990), foi multiplicado pelo fator 6,38 para determinação da PB do mesmo.

\section{Resultados e Discussão}

Os consumos médios diários de MS, $\mathrm{MO}, \mathrm{PB}, \mathrm{EE}$, CHO, FDN, CNF e NDT são apresentados na Tabela 5.

O consumo de MS não diferiu entre as dietas, independentemente da forma expressa. O valor médio diário de consumo neste estudo foi de $18,73 \mathrm{~kg}$ de $\mathrm{MS}$, equivalente a $3,32 \%$ do peso vivo ou $161,78 \mathrm{~g} / \mathrm{kg}^{0,75}$.

Talvez o consumo de MS não tenha diferido entre os tratamentos por estar dentro do nível de inclusão de polpa cítrica de até $30 \%$ da MS total da dieta, recomendado por Ammerman \& Henry (1991), e de $20 \%$, recomendado por Carvalho (1995). Para níveis acima de 20\%, Carvalho (1995) recomenda analisar a relação cálcio e fósforo da dieta, pois a polpa cítrica é rica em cálcio e pobre em fósforo.

Resultados semelhantes foram encontrados por Menezes Jr et al. (2000), que não observaram diferença no consumo de MS quando incluíram polpa cítrica e grão de milho processado em dietas de vacas em lactação, onde registraram consumo médio diário de MS de 19,4 kg, estando 0,7 kg acima do encontrado no presente estudo. Belibasakis \& Tsirgogianni (1995) também não encontraram diferença no consumo de MS das dietas experimentais contendo ou não polpa cítrica, observando consumos médios diários de MS de $18,7 \mathrm{~kg}$, média igual à encontrada no atual estudo.

Entretanto, Nussio et al. (2000), em estudo onde avaliaram diferentes processamentos do grão do milho (moído fino ou grosso e floculado) e inclusão de polpa cítrica, observaram que a polpa cítrica estimulou o consumo de MS, quando combinada com milho moído fino (19,6 kg de MS), mas não com milho floculado (16,1 $\mathrm{kg}$ de MS).
Como polpa cítrica apresenta alto teor de cálcio, as rações foram formuladas para atenderem aos requerimentos deste nutriente. Dessa forma, e principalmente por não haver diferença no consumo de MS entre os tratamentos, os consumos de MO e de CT mantiveram-se constantes nas diferentes dietas.

O teor médio de FDN das dietas foi de $46,6 \%$ estando bem acima daquele sugerido por Mertens (1983), citado por Allen (1991), que está entre 34 a $38 \%$ para vacas produzindo 16 a $24 \mathrm{~kg}$ de leite corrigido para $4 \%$ de gordura. Este teor médio de FDN da dieta está associado ao teor de FDN do volumoso na dieta que atingiu o teor médio de $68,1 \%$. Dessa forma, o consumo de FDN em relação ao peso vivo foi de $1,55 \%$, acima do valor de $1,2 \pm 0,1 \%$ peso vivo sugerido por Mertens (1996), como valor para se obter consumo ótimo de MS. Porém, no Brasil, vários autores encontraram consumos de FDN entre 1,3 e 1,6\% de peso vivo (Araújo, 1995; Malafaia, 1996; Almeida, 1997; Campos, 1998; Moreira, 2000), podendo ser uma adaptação dos animais às forrageiras tropicais.

Constam na Tabela 6 as exigências recomendadas pelo NRC (1989) e NRC (2001) e os consumos observados no presente estudo de PB e NDT.

Não houve diferença para os consumos de PB, observando-se valor médio de $2,86 \mathrm{~kg}$, que está acima em 0,4 kg PB em relação ao recomendado pelo NRC (1989), conforme pode-se visualizar na Tabela 6. Porém, a diferença encontrada de PB recomendado pelo NRC (2001) e do presente estudo foi de $-0,17 \mathrm{~kg}$ PB. Este resultado pode ser atribuído à evolução no cálculo das exigências de $\mathrm{PB}$, obtendo-se maior precisão entre o recomendado e consumido. Também, a porcentagem de PB na MS consumida, que foi $15,2 \%$, está acima do teor utilizado no balanceamento da dieta como mostra a Tabela 4, mostrando a capacidade que o animal tem em selecionar os alimentos, mesmo estes estando na forma de dieta completa. Como as dietas foram balanceadas para serem isoprotéicas e os consumos de MS e MO não diferiram entre os tratamentos, podem ter sido estes os fatores que mais contribuíram para não haver diferença no consumo de PB.

O consumo de NDT não diferiu entre tratamentos, sendo encontrado consumo médio de $13,45 \mathrm{~kg}$ estando acima 1,61 e $1,74 \mathrm{~kg}$ das recomendações do NRC (1989) e NRC (2001) que são de aproximadamente 11,84 e $11,71 \mathrm{~kg}$ de NDT na dieta. Este fato pode estar relacionado a seleção animal que aumentou o consumo de NDT. 
Tabela 5 - Consumos médios diários de matéria seca (MS), matéria orgânica (MO), proteína bruta (PB), extrato etéreo $(E E)$, carboidratos totais $(\mathrm{CHO})$, fibra em detergente neutro (FDN), carboidratos não fibrosos (CNF) e nutrientes digestíveis totais (NDT) das dietas experimentais e suas respectivas médias e coeficiente de variação (CV)

Table 5 - Average daily intakes of dry matter (DM), organic matter (OM), crude protein (CP), ether extract (EE), total carbohydrates (CHO), neutral detergent fiber (NDF), nonstructural carbohydrates (NSC) and total digestible nutrients (TDN) of experimentals diets and average and coefficient of variation (CV)

\begin{tabular}{|c|c|c|c|c|c|c|}
\hline \multirow[t]{2}{*}{$\begin{array}{l}\text { Itens } \\
\text { Items }\end{array}$} & \multicolumn{4}{|c|}{$\begin{array}{c}\text { Nível de polpa cítrica (\%) } \\
\text { Citrus pulp level (\%) }\end{array}$} & \multirow[t]{2}{*}{$\begin{array}{c}\text { Média geral } \\
\text { Average }\end{array}$} & \multirow[t]{2}{*}{$\mathrm{CV}(\%)$} \\
\hline & 0 & 33 & 67 & 100 & & \\
\hline \multicolumn{7}{|c|}{$\begin{array}{l}\text { Consumo (kg/dia) } \\
\text { Intake (kg/day) }\end{array}$} \\
\hline $\begin{array}{l}\text { MS } \\
D M\end{array}$ & 18,56 & 18,72 & 19,06 & 18,59 & $Y=18,73$ & 6,14 \\
\hline $\begin{array}{l}\mathrm{MO} \\
\mathrm{OM}\end{array}$ & 17,23 & 17,58 & 17,72 & 17,22 & $Y=17,44$ & 6,32 \\
\hline $\begin{array}{l}\mathrm{PB} \\
C P\end{array}$ & 2,87 & 2,71 & 2,95 & 2,92 & $Y=2,86$ & 5,83 \\
\hline $\begin{array}{l}\mathrm{EE} \\
E E\end{array}$ & 0,595 & 0,507 & 0,553 & 0,526 & $*$ & 10,06 \\
\hline $\begin{array}{l}\mathrm{CHO} \\
\mathrm{CHO}\end{array}$ & 13,76 & 14,36 & 14,21 & 13,77 & $Y=14,02$ & 7,14 \\
\hline $\begin{array}{l}\text { FDN } \\
N D F\end{array}$ & 9,08 & 7,97 & 9,03 & 8,88 & $Y=8,74$ & 13,35 \\
\hline $\begin{array}{l}\mathrm{CNF} \\
N S C\end{array}$ & 4,67 & 6,38 & 5,17 & 4,89 & $Y=5,28$ & 29,92 \\
\hline $\begin{array}{l}\text { NDT } \\
T D N \\
\end{array}$ & 13,44 & 13,45 & 13,76 & 13,15 & $Y=13,45$ & 7,48 \\
\hline \multicolumn{7}{|c|}{$\begin{array}{c}\text { Consumos }(\% \mathrm{PV}) \\
\text { Intake }(\% L W)\end{array}$} \\
\hline $\begin{array}{l}\mathrm{MS} \\
D M\end{array}$ & 3,30 & 3,30 & 3,38 & 3,28 & $Y=3,32$ & 5,75 \\
\hline $\begin{array}{l}\text { FDN } \\
N D F\end{array}$ & 1,62 & 1,41 & 1,61 & 1,57 & $Y=1,55$ & 14,04 \\
\hline \multicolumn{7}{|c|}{$\begin{array}{c}\text { Consumo }\left(\mathrm{g} / \mathrm{kg}^{0,75}\right) \\
\text { Intake }\left(\mathrm{g} / \mathrm{kg}^{0.75}\right)\end{array}$} \\
\hline $\begin{array}{l}\mathrm{MS} \\
D M\end{array}$ & 160,87 & 161,26 & 164,94 & 160,06 & $Y=161,78$ & 5,81 \\
\hline
\end{tabular}

* Significativo a $5 \%$ de probabilidade ( ${ }^{*}$ significant at $5 \%$ of probability).

Equação de regressão (Regression equation): $Y=0,569543-0,0004741 \mathrm{P} ; \mathrm{R}^{2}=0,29$.

$\mathrm{P}=$ Nível de polpa cítrica no concentrado $(\%)(P=\%$ Citrus pulp content in the concentrate).

Houve decréscimo linear $(\mathrm{P}<0,05)$ no consumo de EE em $0,47 \mathrm{~g}$ de EE/dia para cada $1 \%$ de substituição do milho pela polpa cítrica. Este resultado pode ser explicado pelo decréscimo de EE na dieta, devido à substituição do fubá de milho pela polpa cítrica (Tabelas 3 e 4).

Os valores médios obtidos para a PL, PLG e teores de G, EST, ESD e PB do leite são apresentados na Tabela 7.

Não houve diferença entre os níveis substituição do milho pela polpa cítrica, para PL ou PLG para 4\% de gordura. Isto pode ser explicado pelo fato de o consumo dos nutrientes não ter sido diferente entre os tratamentos.

Os resultados de produção de leite obtidos nesta pesquisa corroboram aqueles obtidos por Belibasakis \& Tsirgogianni (1996), que utilizaram 20 vacas Holandesas com 80 a 130 dias pós-parto e não observaram diferenças para produção de leite corrigida ou não para gordura (24,4 e 23,4 kg de leite/dia). Resultados semelhantes foram encontrados por Ítavo (1998), quando substituiu a silagem de milho pela silagem de bagaço de laranja em 0, 25, 50 e $75 \%$ da matéria seca.

Entretanto, Drude et al. (1971), Van Horn et al. (1975) e Lucci et al. (1975), citados por Carvalho (1995), Nussio et al. (2000) e Menezes Jr. et al. (2000) encontraram maiores produções de leite corrigido para gordura para os tratamentos que continham níveis crescentes de polpa cítrica. 
Tabela 6 - Exigências (E) de proteína bruta (PB) e nutrientes digestíveis totais (NDT) para vacas com $568 \mathrm{~kg}$ de peso vivo produzindo $20,5 \mathrm{~kg}$ de leite/dia com $4,5 \%$ de gordura e ganho de peso de $330 \mathrm{~g} / \mathrm{dia}$ recomendadas pelo NRC (1989) e NRC (2001) e consumo (C) destes nutrientes observado e suas percentagens na matéria seca (MS)

Table 6 - Requeriments $(R)$ of crude protein $(C P)$ and total digestives nutrients (TDN) for the cows with $568 \mathrm{~kg}$ live weight producing $20.5 \mathrm{~kg}$ of milk/day with $4.5 \%$ fat and $330 \mathrm{~g}$ gain/day of live weight, according to NRC (1989) and NRC (2001) and intake (I) of these nutrients observed in the present study and its percentagens in the dry matter

\begin{tabular}{|c|c|c|c|c|c|c|}
\hline \multirow{4}{*}{$\begin{array}{l}\text { Itens } \\
\text { Items }\end{array}$} & \multirow{2}{*}{\multicolumn{3}{|c|}{$\begin{array}{l}\mathrm{PB} \\
C P\end{array}$}} & \multirow{2}{*}{\multicolumn{3}{|c|}{$\begin{array}{l}\text { NDT } \\
T D N\end{array}$}} \\
\hline & & & & & & \\
\hline & \multicolumn{2}{|c|}{$\mathrm{E}(R)$} & \multirow[t]{2}{*}{ C (I) } & \multicolumn{2}{|c|}{$\mathrm{E}(R)$} & \multirow[t]{2}{*}{$\mathrm{C}(I)$} \\
\hline & 1989 & 2001 & & 1989 & 2001 & \\
\hline $\begin{array}{l}\mathrm{kg} / \mathrm{dia} \\
\mathrm{kg} / \text { day }\end{array}$ & 2,46 & 3,03 & 2,86 & 11,84 & 11,71 & 13,45 \\
\hline $\begin{array}{l}\text { Diferença }{ }^{1}(\mathrm{~kg} / \text { dia }) \\
\text { Diference }(\mathrm{kg} / \text { day })\end{array}$ & 0,40 & $-0,17$ & & 1,61 & 1,74 & \\
\hline MS \% & 13,9 & 16,3 & 15,2 & 66,9 & 63,0 & 71,8 \\
\hline
\end{tabular}

$\% D M$

${ }^{1}$ Consumido -Exigência (intake-requeriment).

Contrários a todos os resultados encontrados estão os observados por Leiva et al. (2000), onde a produção de leite com e sem correção para gordura e proteína foi maior 3,9 e 2,6 kg de leite/dia para o tratamento cuja fonte energética foi amido. Também, Sutton et al. (1987) encontraram aumento de $22 \%$ na produção de leite de vacas, quando estas receberam dietas com níveis de $80 \%$ de concentrado amiláceos, em relação ao mesmo nível com polpa cítrica, porém os autores comentaram que houve severa depressão no teor de gordura do leite.

Quanto à composição do leite, não houve diferença para os tratamentos nos teores de G, PB, EST e ESD, conforme pode ser observado na Tabela 7, tal fato pode ser atribuído ao consumo semelhante de FDN. Isto implica que, independente da dieta, o nível de FDN foi mais que suficiente para evitar qualquer possível depressão do teor de gordura. Também não houve diferença entre os tratamentos para consumo de PB (Tabela 5), contribuindo para não alterar o teor de PB do leite.

Estes resultados são contrários aos obtidos por Leiva et al. (2000), que verificaram maior teor de gordura $(+0,18 \%)$ e uréia no leite $(0,76 \mathrm{mg} / 100 \mathrm{~mL})$ na dieta que continha polpa cítrica.

Vários autores (Drude et al., 1971; Van Horn et al., 1975; Lucci et al., 1975, citados por Carvalho 1995, Nussio et al., 2000; Menezes Jr. et al., 2000) verificaram que o teor de gordura foi maior para dietas contendo polpa cítrica. Todavia, estes mesmos autores não encontraram diferença para o teor de PB do leite, assim como Belibasakis \& Tsirgogianni (1996) também não observaram diferença para ESD.

A variação de peso médio diário no presente estudo foi de $+433 \mathrm{~g} /$ dia, mostrando que as dietas garantiram a produção de leite juntamente com ganho de massa corporal, como pode ser observado na Tabela 6. Isto também pode ser explicado em virtude de as vacas estarem no terço médio do seu estádio

Tabela 7 - Produções médias diárias de leite (PL) e com correção para 4\% de gordura (PLG) e composição média do leite de vacas recebendo diferentes níveis de polpa cítrica e suas respectivas médias e coeficientes de variação $(\mathrm{CV})$

Table 7 - Average daily milk production without (MP) and with correction for 4\% fat (MPF) and average milk composition of cows fed different levels of citrus pulp and its respective averages and coefficients of variation

\begin{tabular}{|c|c|c|c|c|c|c|}
\hline \multirow[t]{2}{*}{$\begin{array}{l}\text { Itens } \\
\text { Items }\end{array}$} & \multicolumn{4}{|c|}{$\begin{array}{l}\text { Nível de polpa cítrica (\%) } \\
\text { Citrus pulp level (\%) }\end{array}$} & \multirow[t]{2}{*}{$\begin{array}{l}\text { Média geral } \\
\text { Average }\end{array}$} & \multirow[t]{2}{*}{$\mathrm{CV}(\%)$} \\
\hline & 0 & 33 & 67 & 100 & & \\
\hline $\begin{array}{l}\mathrm{PL}(\mathrm{kg} / \mathrm{vaca} / \mathrm{dia}) \\
M P(\mathrm{~kg} / \text { day })\end{array}$ & 20,2 & 20,7 & 20,6 & 20,5 & $\mathrm{Y}=20,5$ & 5,92 \\
\hline $\begin{array}{l}\mathrm{PLG}(\mathrm{kg} / \mathrm{vaca} / \mathrm{dia}) \\
M P F(\mathrm{~kg} / \text { day })\end{array}$ & 21,9 & 22,2 & 22,4 & 22,5 & $\mathrm{Y}=22,2$ & 5,83 \\
\hline $\begin{array}{l}\text { Gordura }(\%) \\
\text { Fat } \%)\end{array}$ & 4,55 & 4,49 & 4,57 & 4,63 & $Y=4,56$ & 3,99 \\
\hline $\begin{array}{l}\text { Proteína (\%) } \\
\text { Protein (\%) }\end{array}$ & 3,52 & 3,51 & 3,52 & 3,52 & $Y=3,52$ & 3,20 \\
\hline $\begin{array}{l}\text { Extrato seco total (\%) } \\
\text { Total dry extract (\%) }\end{array}$ & 13,86 & 13,91 & 13,68 & 13,92 & $\mathrm{Y}=13,84$ & 3,42 \\
\hline $\begin{array}{l}\text { Extrato seco desengordurado (\%) } \\
\text { Degreased dry extract }(\%)\end{array}$ & 9,31 & 9,42 & 9,32 & 9,28 & $Y=9,35$ & 3,44 \\
\hline
\end{tabular}


lactacional, caracterizado pela partição dos nutrientes favorável ao restabelecimento da condição corporal.

Apesar de as dietas não terem afetado nenhuma variável avaliada neste trabalho, exceto $\mathrm{EE}$, a economicidade mostrou-se vantajosa para os níveis crescentes de polpa cítrica. A margem bruta relativa aos tratamentos contendo polpa cítrica nos níveis de substituição 33, 67 e 100\% foi superior ao tratamento com $0 \%$ de polpa cítrica em 17,5; 37,5 e 52,5\%. Também, o maior nível de substituição do fubá de milho pela polpa cítrica proporcionou a redução no custo de $\mathrm{R} \$ 0,01 /$ litro de leite ou 4,6 pontos percentuais.

\section{Conclusões}

O milho grão pode ser substituído em $100 \%$ por polpa cítrica peletizada em rações concentradas e balanceadas, inclusive para cálcio, para vacas produzindo, em média, $20 \mathrm{~kg}$ de leite. A decisão da inclusão de polpa cítrica na dieta de vacas em lactação dependerá apenas de fatores econômicos.

\section{Agradecimento}

À Universidade Federal de Viçosa; ao Departamento de Zootecnia da UFV; e à empresa Agroceres Nutrição Animal, pelo apoio.

\section{Literatura Citada}

ALLEN, M.S. Carbohydrate nutrition. Food animal practice. Dairy nutrition management. The Veterinary Clinics of North America, v.7, n.2, 1991.

ALMEIDA, R.G. Saccharina em dietas para vacas lactantes. Viçosa, MG: Universidade Federal Viçosa, 1997. 52p. Dissertação (Mestrado em Zootecnia) - Universidade Federal de Viçosa, 1997.

ARAÚJO, G.G.L.; SILVA, J.F.C.; VALADARES FILHO, S.C. et al. Efeito da degradabilidade da proteína sobre o consumo e digestão de matéria seca, matéria orgânica e carboidratos estruturais, em vacas lactantes. Revista da Sociedade Brasileira Zootecnia, v.24, n.3, p.371-381, 1995.

Associação Brasileira dos Exportadores de Citrus. ABECITRUS. URL: http://www.abecitrus.com.br. Consultado em janeiro de 2001.

AMMERMAN, C.B.; HENRY, P.R. Citrus and vegetable products for ruminant animals. In: Proceedings, Alternative Feeds for Dairy and Beef Cattle, St Louis, MO, 1991, p.103-110.

BEHMER, M.L.A. Tecnologia do leite: produção, industrialização e análise. 13.ed. São Paulo: Nobel, 1984. p.100-108.

BELIBASAKIS, N.G.; TSIRGOGIANNI, D. Effects of dried citrus pulp on milk yield, milk composition and blood components of dairy cows. Animal Feed Science and Technology, v.60, p.87-92, 1996.
BELÉM, P.A.D.; SOARES FILHO, P.M. Síndrome hemorrágica, prurido e febre em bovinos alimentados com polpa cítrica. Jornal do Conselho Regional de Medicina Veterinária e Zootecnia do Estado de Minas Gerais, ano XIV, n.64, 1999.

CAMPOS, J.M.S. Balanço dietético cátion-ânion na alimentação de vacas leiteiras, no período do pré-parto. Belo Horizonte: Universidade Federal de Minas Gerais, 1998. 103p. Tese (Doutorado em Zootecnia) - Universidade Federal de Minas Gerais, 1998.

CARVALHO, P.M. Citrus. In: SIMPÓSIO SOBRE NUTRIÇÃO DE BOVINOS. UTILIZAÇÃO DE RESÍDUOS CULTURAIS E BENEFECIAMENTO NA ALIMENTAÇÃO DE BOVINOS, 6., 1995, Piracicaba. Anais... Piracicaba, Fundação de Estudos Agrários Luiz de Queiroz, 1995. p.171-214.

DRUDE, R.E.; ESCANO, J.R.; RUSOFF, L.L. Value of complete feeds containig combinations of corn silage, alfafa pellets, citrus pulp, and cottonseed hulls for lactating cows. Journal Dairy Science, v.54, p.773, 1971.

ÍTAVO, L.C.V. Estudo e utilização da silagem do bagaço de laranja. Maringá: Universidade Estadual de Maringá, 1998. 54p. Dissertação (Mestrado em Zootecnia) - Universidade Estadual de Maringá, 1998.

LEIVA. E.; HALL, M.B.; Van HORN, H.H. Performance of dairy cattle fed citrus pulp or corn products as sources of neutral detergent - soluble carbohydrates. Journal of Dairy Science, v.83, n.12, p.2866-2875, 2000.

MADRID, J.; HERNÁNDEZ, F.; PULGAR, M.A. et al. Urea and citrus by-product supplementation of straw-based diets for goats: effect on barley straw digestibility. Small Ruminant Research, v.24, p.149-155, 1997.

MALAFAIA, P.A.M.; VALADARES FILHO, S.C.; SILVA, J.F.C. et al. Sebo bovino em rações para vacas em lactação 1 . Consumo dos nutrientes, produção e composição do leite. Revista da Sociedade Brasileira Zootecnia, v.25, n.1, p.153-163, 1996.

MENEZES JR., M.P.; SANTOS, F.A.P.; GUIDI, M.T. et al. Processamento do grão de milho e sua substituição parcial por polpa de citros sobre os Itens ruminais e composição do leite de vacas holandesas. In: REUNIÃO DA SOCIEDADE BRASILEIRA DE ZOOTECNIA, 37., 2000, Viçosa, MG. Anais... Viçosa: Sociedade Brasileira de Zootecnia, 2000.

MERTENS, D.R. Comparing forage sources in dairy rations containing similar neutral detergent fiber concentrations. In: UNITED STATES DAIRY FORAGE RESEARCH CENTER, 1995. Research Summaries. USDA, ARS, 1996. p. 87-90.

MOREIRA, A.L. Valor nutritivo de rações contendo silagem de milho e fenos de alfafa e de coast-cross como volumosos, para vacas lactantes e ovinos. Viçosa, MG: Universidade Federal de Viçosa, 2000. 62 p. Dissertação (Mestrado em Zootecnia) - Universidade Federal de Viçosa, 2000.

NATIONAL RESEARCH COUNCIL - NRC. Nutrient requirements of dairy cattle. 6.ed. Washington, D.C.: National Academy Press, 1989. 157p.

NATIONAL RESEARCH COUNCIL - NRC. Nutrient requirements of dairy cattle. 7.ed. Washington, D.C.: National Academy Press, 2001. 381p.

SILVA NETO, J. Economia de escala na produção de leite. Revista Brasileira de Agropecuária, n.7, p.20-22, 2000.

NUSSIO, C.M.B.; SANTOS, F.A.P.; PIRES, A.V. et al. Efeito do processamento do milho e sua substituição por polpa de citros peletizada sobre consumo de matéria seca, produção e composição de leite de vacas em lactação. In: REUNIÃO DA 
SOCIEDADE BRASILEIRA DE ZOOTECNIA, 37., 2000, Viçosa, MG. Anais... Viçosa, MG: Sociedade Brasileira de Zootecnia, 2000.

ROCHA FILHO, R. R. Efeitos da polpa de citrus e do milho sobre Itens ruminais. Piracicaba: Escola Superior de Agricultura "Luiz de Queiroz", 1998. 71 p. Dissertação (Mestrado em Agronomia) - Escola Superior de Agricultura "Luiz de Queiroz", 1998.

SILVA, D.J. Análise de alimentos: métodos químicos e biológicos. Viçosa, MG: Universidade Federal de Viçosa, 1990. $165 \mathrm{p}$.

SNIFFEN, C.J.; O'CONNOR, J.D.; Van SOEST, P.J. et al. A net carbohydrate and protein system for evaluating cattle diets; II. Carbohydrate and protein availability. Journal of Animal Science, v.70, n.11, p.3562-3577, 1992.

SUTTON, J.D.; BINES, J.A.; MORANTI, S.V. et al. A comparison of starchy and fibrous concentrates for milk production, energy utilization and hay intake by Friesian cows. Journal of Agricultural Science, v.109, p.375-386, 1987.
UNIVERSIDADE FEDERAL DE VIÇOSA - UFV. S.A.E.G. Sistema de Análises Estatísticas e Genéticas. Viçosa, MG, 1997 (Versão 7.0).

Van HORN, H.S.; MARSHALL, S.P.; WILCOX, J.C. et al. Complete rations for dairy cattle. 1ll. Evaluation of protein percent and quality and citrus pulp-corn substitutions. Journal Dairy Science, v.58, p.1101-1108, 1975.

Recebido em: 17/06/02

Aceito em: 03/02/03 